\title{
Fomento florestal e sua função socioeconômica: estudo de caso no município de Almeirim (PA)
}

\section{The socio-economic dimensions of forest out-grower schemes in Amazonia: a case study of eucalyptus production in Almeirim (PA)}

Amanda Estefânia de Melo Ferreira - Universidade Estadual do Pará (UEPA), mestre em Ciências Ambientais, professora assistente do curso de Engenharia Ambiental na Universidade do Estado do Pará (UEPA), BelémPA. E-mail: amandaestefania@gmail.com

Luke Thomas Wyn Parry - Lancaster University (Reino Unido), Ph. D. in Environmental Sciences, University of East Anglia, professor em Serviços Ambientais em Lancaster University (Reino Unido). E-mail: lukeparry1@ gmail.com

Bernard Josiah Barlow - Lancaster University (Reino Unido), Ph.D. University of East Anglia (2003), professor sênior no Centro Ambiental em Lancaster University, docente colaborador dos programas de pós-graduação das Universidades Federais do Pará e de Lavras. E-mail: josbarlow@gmail.com

Ima Célia Guimarães Vieira - Ph.D. em Ecologia, Stirling University, pesquisadora do Museu Paraense Emilio Goeldi, Belém-PA. E-mail: ima@museu-goeldi.br

Thiago Fonseca Morelo - Universidade Federal do ABC, doutor em Economia do Desenvolvimento, professor da Universidade Federal do ABC, Centro de Engenharia, Modelagem e Ciências Sociais. E-mail: fonseca. morello@ufabc.edu.br

\section{Resumo}

Os contratos de "fomento florestal" vêm difundindo-se ao longo do território nacional, incluindo a Amazônia. Trata-se de arranjos produtivos entre empresas e produtores locais, com impactos relevantes sobre a renda familiar e fluxos de migração ruralurbana. O artigo analisa evidências acerca da manifestação no presente e no futuro destes benefícios, focalizando uma comunidade de agricultores familiares de Almeirim (PA). Foram entrevistadas 39 famílias. Resulta que os projetos de fomento florestal ofereceram baixa remuneração de mão de obra familiar e se mostram inviáveis quando a contratação de mão de obra faz-se necessária. Os resultados evidenciam que é preciso desenhar contratos de fomento florestal que se adéquem às condições socioeconômicas, ambientais e produtivas dos grupos-alvo.

\section{Palavras-chave}

Silvicultura. Amazônia. Renda per capita. Mão de obra familiar.

\begin{abstract}
Forest out-grower schemes "fomento florestal" are expanding in Brazilian, including Amazonia. This study examined the socio-economic implications of smallholder-led fomento florestal for eucalyptus production in Almeirim (PA). We interviewed both participating and nonparticipating farming households (total = 39). The projects offered low remuneration for household labor input and appeared to be financially unviable when contracted labour was necessary. The implementation of smallholder-led fomento florestal in farms with low capacity can cause a net reduction in income. This study provides an important baseline from which to redefine government policies relevant to the on-going expansion of fomento and development in the Amazon region.
\end{abstract}

\section{Keywords}

Silviculture. Amazon region. Per capita income. Family agriculture. 


\section{INTRODUÇÃO}

No Brasil, empresas de base florestal dos setores de papel e celulose, siderurgia a carvão vegetal e desdobramento de madeira estão adotando o fomento florestal para expandir suas plantações, que nada mais é do que uma forma específica de out-grower scheme, uma parceria contratualizada entre produtores ou proprietários fundiários e uma empresa, para a produção de produtos florestais com valor comercial (DESMOND; RACE, 2001).

O fomento florestal consiste em uma relação contratual envolvendo duas contrapartes: (i) uma empresa de base florestal, que visa obter lucro a partir do processamento da biomassa de espécies arbóreas; e (ii) um produtor rural, que visa obter lucro a partir do uso produtivo de sua terra. Em termos gerais, o contrato funciona de maneira que as duas contrapartes compartilhem custos e benefícios do suprimento da planta de processamento com biomassa (DESMOND; RACE, 2001; MORELLO, 2009; ABRAF, 2007; KAMARA et al., 2011).

As regras que compõem os contratos de fomento florestal tendem a variar entre empresas de base florestal (FISCHER, 2007), e é comum que uma mesma empresa empregue mais de um modelo contratual (SILVA et al., 2009). A empresa de base florestal, em geral, tem como dever adiantar alguns dos insumos necessários ao cultivo arbóreo e prestar serviços de assistência técnica. Em alguns casos, fica estabelecido que a empresa deve conceder ou intermediar a concessão de crédito para o financiamento de despesas em mão de obra (familiar, em alguns casos) e/ou aquisição de insumos e/ou uso/aluguel de máquinas e equipamentos

O produtor rural tem como dever conduzir a plantação arbórea, administrando despesas e supervisionando a mão de obra, de modo a obter uma quantidade de biomassa dentro de um prazo pré-estabelecido. Sendo mais comuns os contratos com duração de apenas uma rotação florestal (intervalo entre plantio e colheita), isto é, de seis a sete anos.

O fomento florestal levou quase 40 anos para se consolidar no Brasil (FERREIRA, 1992) e vem aumentando desde 2005 a uma taxa média anual de 15\%, representando, em 2010, 20,1\% (448.599 hectares) do total de florestas plantadas (ABRAF, 2011).

Entre as principais vantagens econômicas do arranjo há a geração de renda, receita tributária e empregos, fixação de mão de obra da região (ABRAF, 2010; BROEK et al., 2000; GRUPO ORSA, 2010; OLIVEIRA et al., 1998, DESMOND; RACE, 2001). Além disso, trata-se de uma oportunidade para diversificar das atividades produtivas (RIBEIRO; MIRANDA, 2009) e para utilizar terras de baixa aptidão para a agricultura.

Novos Cadernos NAEA • v. 17 n. 1 • p. 75-98 • jun. 2014 
Por outro lado, o fluxo de caixa de pequenos e médios produtores rurais pode não ser compatível com o volume e a frequência dos investimentos requeridos pela silvicultura, e a atividade exige conhecimento específico e assistência técnica (REZENDE et al., 2005, SILVA et al., 2009, HERBOHN; HARRISON, 2004, DEMOND; RACE, 2001, KAMARA et al., 2011). Além disso, instalados em pequenas escalas e distantes dos centros beneficiadores, o fomento florestal pode apresentar baixa rentabilidade aos produtores e as empresas, respectivamente (SILVA, et al., 2009).

Há outros potenciais benefícios de caráter não econômico, como o fato de evitar a concentração fundiária, observada no entorno de empresas de base florestal (RIBEIRO; MIRANDA, 2009; MORELLO, 2009), a inclusão social de pequenos e médios produtores na cadeia produtiva (KAMARA et al., 2011), e a própria transferência de tecnologia por meio da assistência técnica e capacitação do produtor para o desenvolvimento da silvicultura (FISCHER, 2009; GRUPO ORSA, 2010; ROCHADELLI et al., 2008).

Do ponto de vista ambiental, as implicações do fomento florestal decorrem do modelo de silvicultura seguido. No Brasil, trata-se, na maioria dos casos, do monocultivo de eucalipto (uma espécie exótica), cuja plantação impacta a biodiversidade e causa vulnerabilidade a pragas e doenças (VALVERDE, 2007). Este modelo aparece associado na literatura com outros danos ambientais, como a dominância sob a vegetação nativa, o comprometimento dos recursos hídricos (OLIVEIRA et al., 2002; COSSALTER; PYE-SMITH, 2003), a exaustão de recursos minerais do solo (ZIMMERMANN, 2009) e a redução da fauna (BARLOW et al., 2007).

Na Amazônia, o fomento florestal é recente, conhecendo-se apenas os programas com eucalipto da Fundação Orsa e Jarí Celulose, no Vale do Jarí, o maior polo de produção do estado do Pará, que ocupa aproximadamente 60 mil hectares (ha), compartilhados com o estado do Amapá, área que compreende plantios próprios e plantios estabelecidos em terras de produtores agrícolas familiares via fomento, além das experiências com fomento de paricá (Schizolobium amazonicum Huber ex Ducke) em Paragominas.

Neste sentido, o artigo tem objetiva avaliar o potencial do fomento florestal para promover o desenvolvimento local sustentável de uma comunidade de pequenos produtores, localizada na Amazônia brasileira. 


\section{MATERIAIS E MÉTODOS}

\section{Trabalho de campo}

O estudo foi realizado no município de Almeirim (PA), mais especificamente na área de atuação do Grupo Orsa, responsável pela gestão e funcionamento da Empresa Jarí Celulose S.A.

As entrevistas foram realizadas em propriedades rurais com e sem projetos de fomento (FO 'fomentados' e NF 'não fomentados', respectivamente), no período de 22 de outubro a 9 de dezembro de 2010. Para a escolha do universo amostral, foi levado em consideração o número total de 122 fomentados existentes nos cadastros fornecidos pela Fundação Orsa. Definiu-se uma amostra representativa do total de produtores fomentados, com a realização de 20 entrevistas, escolhidas aleatoriamente. Para os não fomentados, as entrevistas foram realizadas com o vizinho mais próximo à propriedade fomentada entrevistada, de modo que a amostra é composta por famílias fomentadas (FO) e famílias não fomentadas vizinhas a famílias fomentadas (NF), totalizando 39 entrevistas. Este número é ímpar, pois, para uma das famílias fomentadas não existia vizinho mais próximo não-fomentado.

\section{Análise de dados}

\section{Características gerais e geração de índices}

Entende-se por características gerais parâmetros como: tamanho médio da propriedade, média do número de pessoas em idade para o trabalho (homens entre 15 e 59 anos, e mulheres entre 15 e 54 anos) e média para o número de pessoas idosas (pessoas acima de 60 anos do sexo masculino e acima de 55 do sexo feminino). Para determinar se os dois grupos (FO e NF) diferem de maneira estatisticamente significativa para cada uma dessas características, empregou-se o teste não paramétrico de Mann-Whitney para os valores médios dos grupos.

Para saber se as atividades de fomento florestal têm afetado a segurança alimentar das famílias, comparou-se a quantidade de farinha comprada para o ano de 2009 entre fomentados e não fomentados, com aplicação de teste de Mann-Whitney.

Para medir o nível de relacionamento institucional entre a empresa e as famílias, e prestação de assistência técnica, foram medidas a ocorrência (eventos em que a empresa visitou as propriedades) de atuação da empresa (Grupo Orsa), prefeituras e Empresa de Assistência Técnica e Extensão Rural (EMATER/PA), e posteriormente aplicado um teste de qui-quadrado.

Novos Cadernos NAEA • v. 17 n. $1 \cdot$ p. 75-98 • jun. 2014 
Para quantificar alguns aspectos qualitativos (qualidade de moradia, nível de interação social, nível de organização e aprendizado) ou de difícil mensuração e análise (quantidade de benfeitorias e equipamentos presentes nos estabelecimentos), foram criados índices cujas médias dos grupos FO e NF foram comparadas (Teste de Mann-Whitney), atribuindo valores de "O" para Não e "1" para Sim para cada item analisado, sendo de 0-12 itens para o índice de benfeitoria; de 0-9 para o índice de equipamentos; 0-4 para o índice de moradia; 0-5 para o índice de sociabilidade; 0-3 para o índice de associativismo e cooperativismo; e 0-5 para o índice de aprendizado.

\section{Análise econômica}

A Renda Bruta Anual (RBA), compreendendo produtos vendidos pelas famílias, foi calculada como a soma de três categorias de renda: agricultura, extrativismo e extra. A primeira compreende cultivos anuais, perenes e criações. A segunda, madeira e produtos florestais não madeireiros. A renda extra compreende emprego na cidade e no campo, venda de mão de obra, benefícios governamentais (bolsa família, aposentadorias, pensões) e atividades pluriativas, dentre outras. A partir da RBA, foi calculada a RBM (renda bruta mensal), dividindo a RBA pela quantidade de meses no ano (12). Dividindo a RBM pelo número médio de pessoas na família, obteve-se a Renda Mensal per capta (RPC), ou ainda, pelo valor atribuído ao salário mínimo para o ano de estudo $(\mathrm{R} \$ 465,00$ em 2009), foi obtida a Renda per capita em salário mínimo (RPS).

A produtividade para a farinha de mandioca por hectare (PFH) é mensurada a partir da razão entre quantidade produzida (sacos/hectare) pela área plantada de mandioca em hectare (APM). A quantidade vendida por hectare (QVH) é calculada a partir da razão da quantidade vendida pela APM. Já a quantidade de farinha consumida por hectare $(\mathrm{QCH})$ é obtida a partir da subtração da PFH pela QVH. Deste modo, pode-se chegar à porcentagem da área plantada que gera renda da mandioca (ARR) por meio da equação: $\mathrm{ARR}=\mathrm{QVH} / \mathrm{PFH} \mathrm{x}$ 100. Finalmente, a área que deve ser implantada para manutenção da renda de mandioca (AMR) é dada por AMR = APM x ARR/100.

A esta medida também foi aplicado o teste não paramétrico de MannWhitney (U) para determinar se o valor por ela assumido difere em magnitude estatisticamente significativa entre fomentados e não fomentados. O mesmo teste foi empregado para as áreas de implantação de cultivos anuais para o ano de 2010 e contrastados com a AMR, para medir a capacidade dos estabelecimentos em manter suas rendas agrícolas. 
O balanço monetário (BM) dos investimentos na atividade de fomento florestal foi calculado por meio da equação: $\mathrm{BM}=\sum \mathrm{RR}-\sum \mathrm{RI}$, onde RR $=$ recursos recebidos e RI = recursos investidos. Já a taxa de embolso e reembolso para cada atividade de fomento (TER, dada em porcentagem) foi obtida por meio da equação: TER $(\%)=(B M$ da atividade $/ \mathrm{RR}$ da atividade $) \times 100$.

O esforço familiar (EFA) para as atividades de fomento durante o ano é dado pela equação: EFA = PDF x ( $\bar{x}$ MOF x NDT), em que: PDF é a parcela do dia destinada ao trabalho na área de fomento, $\bar{x}$ é o símbolo usado para a média, MOF é a mão de obra familiar, e NDT é dado pela multiplicação do número de dias trabalhados por semana (6 dias) pela quantidade de semanas no mês (4 ou 3) pelo número de meses do ano (12). Assim, o esforço familiar por hectare (EFH) pode ser obtido através da EFA, dividido pelo tamanho médio dos projetos de fomento florestal. E, finalmente, dividindo o balando monetário por projeto (BP) pela EFA obtêm-se a compensação por hora trabalhada (CHT).

O nível de capitalização de propriedades FO e NF foi obtido comparando o valor monetário total de bens duráveis domésticos (fogão a gás, freezer, geladeira, máquina de lavar roupas, tanque de lavar roupas, aparelhos de rádio, televisão, celular e DVD, antena parabólica, gerador de energia, bomba d'água, motor rabeta, casa urbana e veículo de transporte). Os preços de cada item foram coletados em trabalho de campo, a exemplo do trabalho semelhante nas cidades de Borba e Nova Arapuanã, no Amazonas, em março de 2011.

\section{RESULTADOS}

\section{Características dos estabelecimentos estudados}

Nesta seção, o valor do teste de Mann-Whitney e o p-valor a ele associado, representados, respectivamente, por " $U$ " e "P", serão reportados para todas as medidas, para as quais foram comparados os dois grupos (FO e NF) entre parêntesis.

O tamanho médio da propriedade não difere estatisticamente entre os dois grupos. Fomentos (FO) têm tamanho médio de 166,3 ha \pm 38,6 EP (Erro Padrão); e não fomentados (NF), em média, possuem tamanho de 156,8 ha \pm 49,3 EP $(\mathrm{U}=147,5 ; \mathrm{P}=0,232)$. A maioria das propriedades possui tamanho entre 51 a 100 ha. Os grupos de produtores estudados apresentam, em sua grande maioria, apenas um domicílio $(\mathrm{FO}=11$; $\mathrm{NF}=14)$, composto por família com 4,9 pessoas $\pm 0,7 \mathrm{EP}(\mathrm{FO})$ e 3,8 pessoas \pm 0,5 EP $(\mathrm{NF})$, em média, por domicílio, e se caracterizam como propriedades agrícolas familiares, de acordo 
com a lei 11.326 (BRASIL, 2006). O ano de início da atividade de fomento florestal também varia entre as famílias: dois agricultores iniciaram em 2006, seis agricultores em 2007, dois em 2008, três em 2009 e sete e 2010.

No que diz respeito às características familiares, fomentados e não fomentados possuem características significantemente diferentes em termos demográficos. Os fomentados possuem famílias maiores ( $\mathrm{FO}=6,2$ pessoas \pm $0,7 \mathrm{EP} ; \mathrm{NF}=3,7$ pessoas $\pm 0,5 \mathrm{EP} ; \mathrm{P}<0,01)$, mais pessoas com idade plena de trabalho $(\mathrm{FO}=6,2$ pessoas \pm 0,7 $\mathrm{EP} ; \mathrm{NF}=3,7$ pessoas \pm 0,5 $\mathrm{EP} ; \mathrm{P}<0,01)$ e menos idosos que os não fomentados $(\mathrm{FO}=4,1$ pessoas $\pm 0,5 \mathrm{EP}$; $\mathrm{NF}=2,1$ pessoas \pm 0,3 EP; $\mathrm{P}<0,01)$.

Os grupos estudados são diferentes ainda na composição de sua renda. Entre fomentados, a agropecuária é a principal fonte de renda, enquanto para não fomentados o principal componente da renda são benefícios recebidos do governo, tais como: aposentadorias, pensões, seguros, entre outros. Os fomentados possuem como base de sua renda agrícola monetária ${ }^{1}$ as criações (anuais $=16,6 \%$, perenes $=2,32 \%$, criações $=20,73 \%$ ), enquanto os não fomentados os cultivos anuais (anuais $=20,75 \%$, perenes $=0,37 \%$, criações $=$ $6,56 \%)$. As rendas extras também merecem destaque pela alta representatividade na renda dos estabelecimentos $(\mathrm{FO}=41,51 \%$; $\mathrm{NF}=36,73 \%)$, conforme demonstrado na Tabela 1.

Tabela 1. Renda bruta anual por atividades/ano, renda bruta total anual, renda bruta total mensal, renda per capita/mês, razão em relação ao salário mínimo para o ano de 2009 per capita para fomentados e não fomentados com médias, erro padrão e teste de Mann-Whitney. $\mathrm{N}_{1}$ é a quantidade de produtores que utilizaram tal atividade para a renda. Enquanto N é toda a amostra; (A) Sem considerar a produção para consumo; (B) Considerando a produção para consumo.

\begin{tabular}{|c|c|c|c|c|c|c|c|c|c|}
\hline & \multicolumn{3}{|c|}{ Fomentados } & \multicolumn{3}{|c|}{ Não fomentados } & \multicolumn{2}{|c|}{ Estatística } \\
\hline & & $\begin{array}{l}\text { Média } \\
(\mathrm{R} \$)\end{array}$ & $\begin{array}{c}\mathrm{EP} \\
(\mathrm{R} \$)\end{array}$ & $\begin{array}{l}\% \mathrm{da} \\
\text { renda }\end{array}$ & $\begin{array}{c}\text { Média } \\
\text { (R\$) }\end{array}$ & $\begin{array}{c}\text { EP } \\
(\mathrm{R} \$)\end{array}$ & $\begin{array}{l}\% \mathrm{da} \\
\text { renda }\end{array}$ & $\mathrm{U}$ & $\mathrm{P}$ \\
\hline Anuais/ano & A & 4392,8 & 2990,1 & 16,6 & 3385,7 & 1711,6 & 20,8 & 108,0 & 0,55 \\
\hline Perenes/ano & A & 614,8 & 454,0 & 2,3 & 60,5 & 54,4 & 0,4 & 107,0 & 0,52 \\
\hline Criações/ano & A & 5489,6 & 3414,3 & 20,7 & 1071,0 & 849,8 & 6,6 & 110,0 & 0,60 \\
\hline Rendas Extras/ano & A & 10994,7 & 4532,7 & 41,5 & 6993,4 & 3512,5 & 36,7 & 105,0 & 0,47 \\
\hline Benefícios/ano & A & 2869,8 & 1819,3 & 10,8 & 3828,6 & 1274,1 & 23,5 & 108,0 & 0,55 \\
\hline Extrativismo/ano & A & 2125,8 & 1012,3 & 8,0 & 977,4 & 891,7 & 6,0 & 96,0 & 0,29 \\
\hline
\end{tabular}

\footnotetext{
Sem levar em consideração o consumo.
} 


\begin{tabular}{l|l|r|r|r|r|r|r|r|r}
\hline Renda Total Anual & A & 26487,4 & 7452,9 & - & 16316,7 & 4302,6 & - & 88,0 & 0,17 \\
\hline Renda Total Mensal & A & 2207,3 & 621,1 & - & 1359,7 & 358,5 & - & & \\
\hline Renda per capita $/$ mês & A & 438,5 & 157,4 & - & 439,1 & 128,9 & - & 113,0 & 0,68 \\
\hline $\begin{array}{l}\text { Renda per capita em } \\
2009 \text { (salário mínimo) }\end{array}$ & A & 0,94 & 0,34 & - & 0,94 & 0,28 & - & & \\
\hline Anuais/ano & B & 5281,34 & 3251,6 & 19,3 & 5389,3 & 1927,3 & 29,4 & 93,0 & 0,24 \\
\hline Renda Total Anual & B & 27376,0 & 7528,5 & - & 18320,3 & 4181,3 & - & 102,0 & 0,41 \\
\hline Renda Total Mensal & B & 2281,3 & 627,4 & - & 1526,7 & 348,4 & - & & \\
\hline Renda per capita $/$ mês & B & 453,2 & 159,3 & - & 498,7 & 128,2 & - & 99,0 & 0,35 \\
\hline $\begin{array}{l}\text { Renda per capita em } \\
\text { 2009 (salário mínimo) }\end{array}$ & B & 0,97 & 0,34 & - & 1,07 & 0,28 & - & & \\
\hline
\end{tabular}

\section{Efeitos do fomento florestal}

\section{Transferência de tecnologia e relações sociais}

As atividades de fomento contribuíram positivamente para a transferência de tecnologia: fomentados (média $=0,85 \pm 0,23 \mathrm{EP}$ técnicas) registram índice de aprendizado significativamente maior $\left(\mathrm{U}_{(20,19)}=122,50 ; \mathrm{P}>0,05\right)$ do que não fomentados (média $=0,26 \pm 0,12 \mathrm{EP}$ técnicas).

Quanto às relações sociais, os produtores rurais fomentados $(3,10 \pm 0,23$ EP) apresentaram maior índice de sociabilidade do que os não fomentados $(2,37 \pm 0,24 \mathrm{EP})$, com diferença fracamente significativa ${ }^{2}(\mathrm{U}=122,5 ; \mathrm{P}=$ 0,057). Quanto à participação em associações e sindicatos, não houve diferença significativa entre fomentados $(1,05 \pm 0,15 \mathrm{EP})$ e não fomentados $(0,79 \pm 0,14$ $\mathrm{EP}),(\mathrm{U}=152,5 ; \mathrm{P}=0,279)$.

Existe uma forte relação institucional entre a empresa fomentadora e os fomentados, com estes $(100 \%)$ recebendo significativamente $\left(x^{2}=29,02\right.$; $\mathrm{P}<0,0001)$ mais assistência técnica do que os não fomentados $(26,3 \%)$. O Grupo Orsa é a instituição prestadora de assistência técnica mais atuante na comunidade: 21/39 estabelecimentos foram atendidos pela Jarí Celulose, 4/39 estabelecimentos pela Fundação Orsa. Em terceiro lugar estão as atividades promovidas pelas prefeituras municipais (3/39 estabelecimentos atendidos) e pela Empresa de Assistência Técnica e Extensão Rural (EMATER) (2/39 estabelecimentos).

\footnotetext{
$\overline{2 \text { Adotou-se } \mathrm{P}}<0,1$ como diferença fracamente significativa.
} 


\section{Efeitos na renda, capitalização e infraestrutura agrícola dos estabeleci- mentos}

No geral, 47\% das famílias estudadas possuem renda per capita abaixo de $1 / 2$ salário mínimo, não existindo diferença significativa entre as rendas per capita dos dois grupos (FO e NF). O fomento florestal ainda não revela sinais de ter exercido efeito significativo na renda per capita das famílias. Apesar de o grupo FO possuir renda total maior, possui também um maior tamanho médio para a família ou equaliza os valores per capita (Tabela 1).

A consideração da produção de anuais (milho, arroz e mandioca) para suprimento do consumo familiar, como parte da renda dos estabelecimentos estudados, leva a renda per capita das famílias não fomentadas (Tabela 1) a tornar-se relativamente maior, apesar da discrepância não ser estatisticamente significativa.

No que tange ao grau de capitalização, o fomento florestal também não mostra impacto significativo $(\mathrm{FO}=10917,6 \mathrm{R} \$ \pm 3312,2 ; \mathrm{NF}==7772,8$ $\mathrm{R} \$ \pm 1870,2 ; \mathrm{P}=0,78)$. Entretanto, quando levadas em consideração as áreas de plantios florestais com retorno garantido por meio do contrato de fomento, a diferença é altamente significativa entre fomentados e não fomentados $(\mathrm{FO}=72431,3 \mathrm{R} \$ \pm 15731,6 ; \mathrm{NF}=7772,8 \mathrm{R} \$ \pm 1870,2 ; \mathrm{P}<0,001)$. Por tratarse de implantação recente, sem que a colheita tenha sido realizada até o momento do estudo, não houve efeito significativo na quantidade de equipamentos $(\mathrm{FO}=2,0$ equipamentos $\pm 0,2 ; \mathrm{NF}=1,9$ equipamentos $\pm 0,3 ; \mathrm{P}=0,62)$, benfeitorias $(\mathrm{FO}=2,0$ benfeitorias $\pm 0,4 ; \mathrm{NF}=2,7$ benfeitorias $\pm 0,5$; $\mathrm{P}=0,42)$ e condições de moradia entre os dois grupos estudados $(\mathrm{FO}=1,0$ itens $\pm 0,2 ; \mathrm{NF}=1,4$ itens $\pm 0,2 ; \mathrm{P}=0,21)$.

\section{Balanço monetário do fomento florestal e remuneração da mão de obra familiar}

No que diz respeito ao investimento financeiro realizado nas atividades de fomento florestal, $40 \%$ dos fomentados encontram-se com balanço monetário negativo na relação entre a quantidade de recursos recebidos (RR) e a quantidade de recursos investidos (RI) na mão de obra para as atividades de fomento, enquanto outra parcela possui balanço positivo (55\%) e 5\% permanece com balanço igual a “zero". Foi observada uma relação entre o balanço monetário e a disponibilidade de mão de obra familiar, onde fomentados com balanço negativo possuem significativamente $\left.\mathrm{U}_{(8,11)}=13,5 ; \mathrm{P}>0,05\right)$ menor disponibilidade (média $=1,21 \pm 0,44 \mathrm{EP}$ pessoas) do que a parcela com saldo positivo (média $=$ 3,10 \pm 0,38 EP), conforme observado na Figura 1 . 
Figura 1. Eixo X - estabelecimentos estudados. Eixo Y - balanço monetário (Reais/ha) entre a quantidade de recursos recebidos e a quantidade de recursos investidos nas atividades de fomento para os estabelecimentos agrícolas estudados (barras cinzas). Eixo Z - disponibilidade e mão de obra familiar (linha preta).

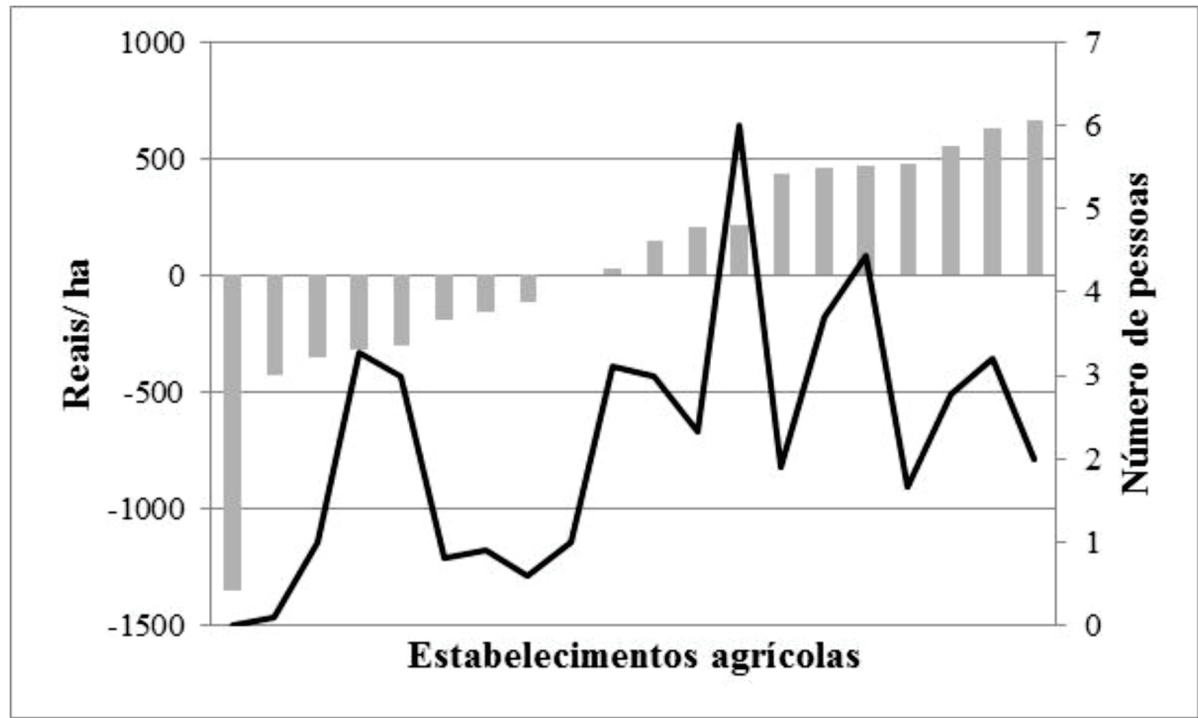

Algumas atividades de manejo em fomento florestal demandam mais mão de obra do que outras, e também maior investimento, tais como limpeza de área, construção de aceiros, coveamento e fosfatagem e limpeza manual. São as que, em média, tornam o balanço negativo pela alta demanda de trabalho ou pela liberação insuficiente de recursos para estas atividades. Por outro lado, as atividades de adubação duram de 0 a 20 dias, adubação de 60 a 90 dias, adubação de um ano , plantio, limpeza química, aplicação de formicida, possuem balanço positivo e alta taxa de embolso. Deixando, dessa forma, um balanço médio por estabelecimento de 53,53 \pm 6,60 EP reais $/$ ha (Figura 2.a) e TER $=145,91 \%$ (Figura 2.b).

Todavia, distribuindo esse valor remanescente pela mão de obra familiar $(2,24 \pm 0,34$ EP pessoas) empregada nas atividades de fomento florestal, com um esforço familiar anual (EFA) aproximado de 173,30 horas/ano, ou com esforço familiar por hectare (EFH) de 26,23 horas/ha, a compensação por hora trabalhada para a família (CHT) é de por volta de $\mathrm{R} \$ 0,38$. Destaca-se, ainda, que não houve relação significativa entre os produtores mais pobres (renda abaixo de $1 / 2$ salário mínimo per capita) e balanços negativos em atividades de fomento $\left(\mathrm{x}^{2}=0,124 ; \mathrm{P}=0,72\right)$ (Figura 3). 
Figura 2.a: Balanço monetário (BM) dos investimentos na atividade de fomento, por atividade: limpeza de área (LA), aceiros (AC), coveamento e fosfatagem (CF), adubação de 0-20 dias (AD1), adubação de 60-90 dias (AD2), adubação de 1 ano (AD3), plantio (PL), limpeza manual (LM), limpeza química (LQ), aplicação de formicida (FOR).

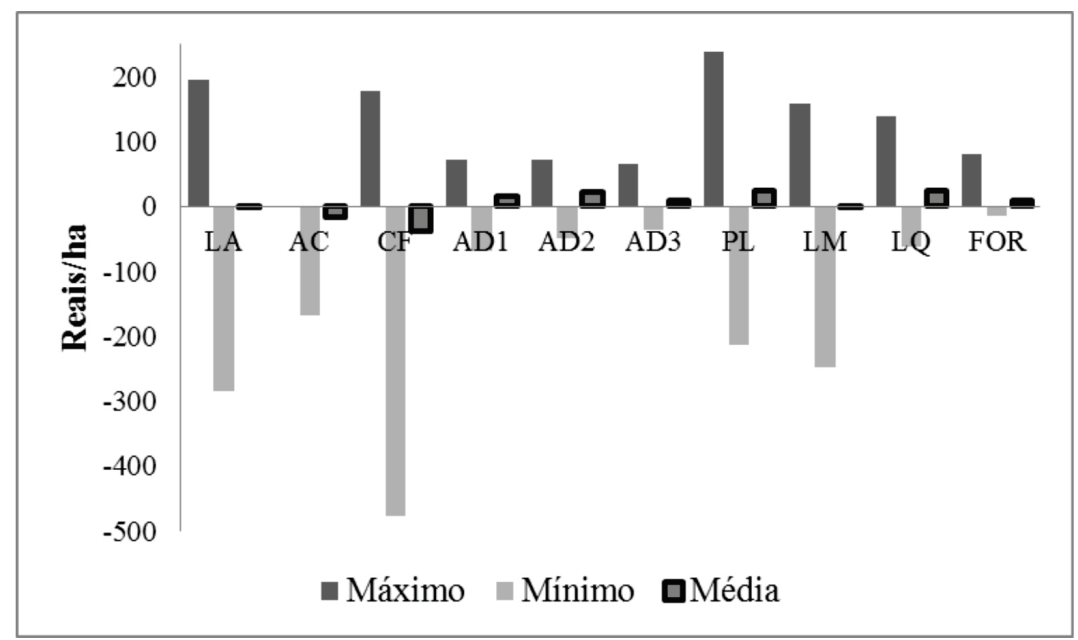

Figura 2.b: Taxa de embolso e reembolso na atividade de fomento, por atividade: limpeza de área (LA), aceiros (AC), coveamento e fosfatagem (CF), adubação de 0-20 dias (AD1), adubação de 60-90 dias (AD2), adubação de 1 ano (AD3), plantio (PL), limpeza manual (LM), limpeza química (LQ), aplicação de formicida (FOR).

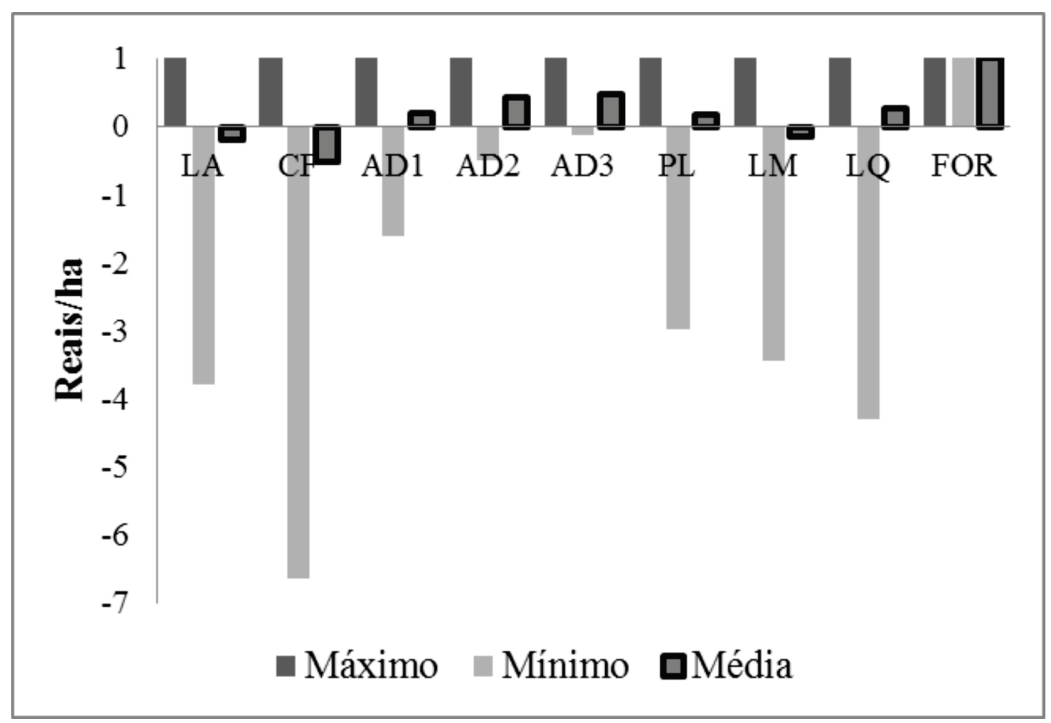


Figura 3: Eixo Y - renda per capita para as famílias fomentadas. Eixo Z - balanço monetário por hectares para essas famílias.

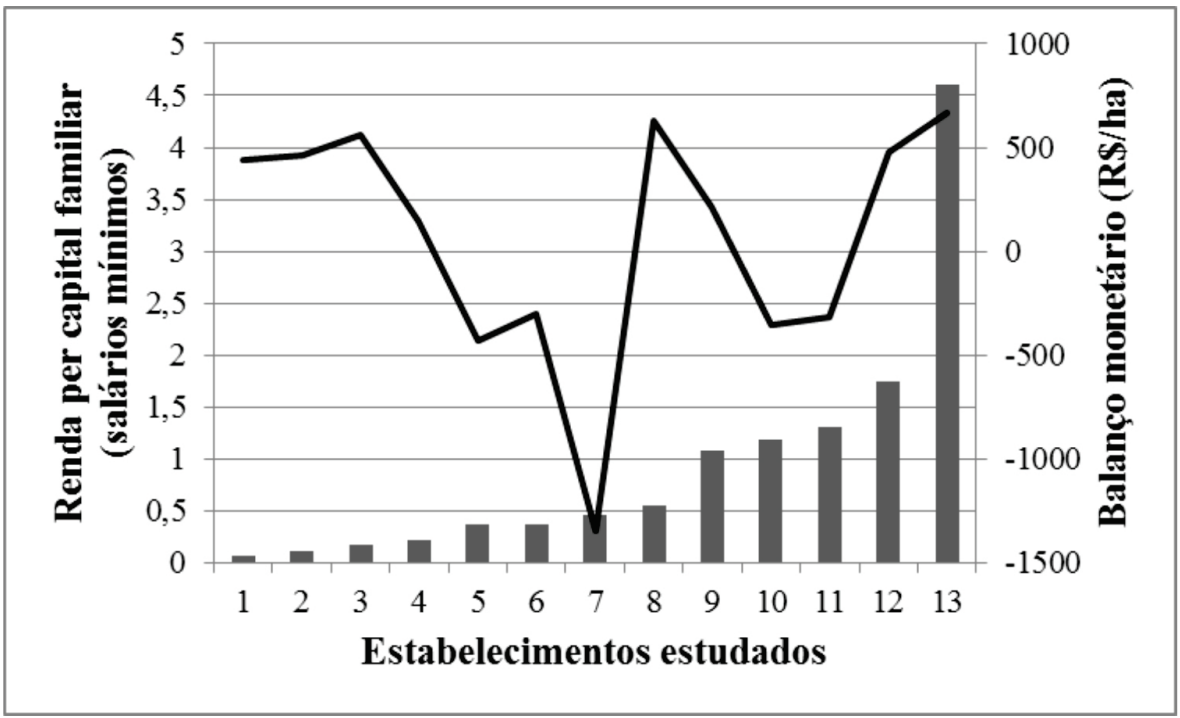

\section{Impactos atuais e possíveis implicações futuras}

A renda monetária gerada pelas culturas anuais é representativa para as famílias de FO e NF, sendo baseada unicamente na produção de farinha. Mesmo assim corresponde à parcela importante da renda total das propriedades $(\mathrm{FO}=$ $16,58 \% ; \mathrm{NF}=20,75 \%$ ). Sendo assim, faz-se necessária a implantação de novas áreas de cultivo de mandioca, de tamanhos equivalentes às já cultivadas, para manter o nível de renda e de consumo associados ao produto. Para o ano de 2009 , fomentados e não fomentados utilizaram, em média, 74,47\% $\%$ 8,55 \% $\mathrm{EP}$ e $68,61 \% \pm 8,74 \%$ EP de suas áreas de plantio, respectivamente, para alcançar a renda de farinha obtida no ano de 2010. Sendo assim, a área necessária para a manutenção da parcela a partir da renda advinda da produção de farinha seria de $1,52 \pm 0,80 \mathrm{EP}$ ha para fomentados e de 1,17 \pm 0,28 EP para não fomentados, sem diferença estatística entre os dois grupos $\left(U_{(5,11)}=21,00 ; \mathrm{P}=0,62\right)$, ver Tabela 2. 
Tabela 2: Tabela de área plantada de mandioca (APM), produtividade de farinha por hectare $(\mathrm{PFH})$, quantidade consumido por hectare $(\mathrm{QCH})$, quantidade vendida por hectare plantado $(\mathrm{QVH})$, porcentagem da área plantada responsável pela renda da mandioca (ARR) e área necessária para manutenção da renda (AMR), com número amostral $(\mathrm{N})$, média e erro padrão para fomentados (FO) e não fomentados (NF). Cálculos feitos usando 2009 como ano base.

\begin{tabular}{l|r|r|r|r|r|r}
\hline & N FO & $\begin{array}{c}\text { Média } \\
\text { FO }\end{array}$ & $\begin{array}{c}\text { Erro Padrão } \\
\text { FO }\end{array}$ & $\begin{array}{c}\text { N } \\
\text { NF }\end{array}$ & $\begin{array}{c}\text { Média } \\
\text { NF }\end{array}$ & $\begin{array}{c}\text { Erro } \\
\text { Padrão NF }\end{array}$ \\
\hline Área plantada (ha) & 5 & 2,10 & 1,10 & 11 & 1,51 & 0,27 \\
\hline Produtividade (saco/ha) & 5 & 72,25 & 31,06 & 11 & 67,03 & 15,06 \\
\hline Consumido (saco/ha) & 5 & 14,25 & 4,99 & 11 & 17,21 & 7,03 \\
\hline Vendida (saco/ha) & 5 & 58,00 & 53,78 & 11 & 49,81 & 14,86 \\
\hline Área de renda (\%) & 5 & 74,47 & 8,55 & 11 & 68,61 & 9,16 \\
\hline Área necessária (ha) & 5 & 1,52 & 0,80 & 11 & 1,17 & 7,03 \\
\hline
\end{tabular}

Contrastando com os dados de áreas de culturas anuais implantadas para o ano de 2010, embora com diferença fracamente significativa ( $U=50,00$; $\mathrm{P}=0,076$ ), fomentados (média $=0,88 \pm 0,39 \mathrm{EP}$ ha) possuem áreas de plantio de anuais menores que não fomentados (média $=1,98 \pm 0,53 \mathrm{EP}$ ha), o que demonstra um impacto negativo do fomento florestal, considerando-se a relevância das culturas anuais para a renda e a segurança alimentar das famílias. Atualmente, 21,7 e 27,7\% (FO e NF, respectivamente) da produção de farinha é consumida pelas famílias. Mesmo não tendo manifestado esses desdobramentos, os fomentados compram mais farinha (média $=164,14 \pm 56,92 \mathrm{EP} \mathrm{kg} /$ ano) do que os não fomentados (média $=81,47 \pm 33,26 \mathrm{EP} \mathrm{kg} /$ ano), o que garante a maior segurança alimentar desses últimos $\left(\mathrm{U}_{(13,19)}=95,5 ; \mathrm{P}=0,28\right)$.

Por outro lado, deve-se ressaltar que em futuro próximo, quando do início das colheitas de eucalipto, a capitalização das famílias fomentadas deverá aumentar aproximadamente 9,32 vezes com a venda das áreas de eucalipto para a empresa fomentadora, já que os contratos de fomento com a empresa (plantios florestais) são retorno garantido dentro de seus ou sete anos.

\section{DISCUSSÃO}

Os resultados permitem mensurar a relevância da adoção de projetos de fomento florestal nos aspectos socioeconômicos de famílias em estabelecimentos 
rurais na Amazônia. Destacam-se três resultados: (i) a adoção de fomento florestal parece estar relacionada às características intrínsecas (tamanho de famílias, faixa etária, disponibilidade de mão de obra e composição da renda total) de cada estabelecimento agrícola, sendo as famílias com fomento geralmente maiores, mais jovens, com maior disponibilidade de mão de obra e com atividades agrícolas de retorno em médio e longo prazos reforçando a renda; (ii) o fomento florestal gera impactos moderados (maior adoção de práticas agrícolas, relações sociais, baixa remuneração da mão de obra familiar) em curto e médio prazos (entre um e sete anos); (iii) os impactos mais relevantes (diminuição da produtividade agrícola, insegurança alimentar e alta capitalização) de implantação de projetos de fomento tendem a se manifestar apenas em longo prazo (a partir de sete anos).

\section{Características peculiares e adoção de fomento florestal}

As diferentes características encontradas nos grupos familiares (demográficas e composição de renda) caracterizam a heterogeneidade do meio dos estabelecimentos estudados, e parece ser um fator preponderante para a adoção de projetos de fomento florestal.

Características familiares são amplamente consideradas como fatores importantes para a tomada de decisão em estabelecimentos agrícolas (CHAYANOV, 1974; HURTIENNE, 2005). Neste contexto, famílias maiores e com mais disponibilidade de força de trabalho estão dispostas a assumir maiores riscos e inovar seus sistemas produtivos (fomentados), enquanto famílias menores, com menor disponibilidade de mão de obra e, principalmente, com maior quantidade de pessoas em idade avançada, não estão tão dispostas a correr riscos com a execução de novos projetos (não fomentados).

Neste sentido, fomentados investem mais em projetos estratégicos que deêm retorno a médio e longo prazos (a partir de quatro anos) como: perenes, gado e silvicultura, mas colocando em risco as atividades em curto prazo (menos de dois anos). Já os não fomentados investem em projetos táticos, que deem retorno em curto prazo (cultivos anuais, hortaliças). Segundo Sebillotte (1987), os objetivos de uma família de agricultores são geralmente apresentados de forma hierarquizada (tático ou de curto prazo, estratégico ou de médio e longo prazos, e global ou que se refira à permanência no meio rural), em que os elementos de um nível permitem atingir objetivos de nível superior, e como objetivos, os quais concorrem os elementos do nível inferior.

Todavia, ao diminuir gradativamente os investimentos em cultivos anuais (fomentados estão plantando menos do que o necessário para manutenção de 
suas rendas atuais, Tabela 2), representativos do nível tático e geração de renda imediata, os fomentados podem estar colocando em risco a sustentabilidade produtiva de seus sistemas de produção, podendo entrar em colapso.

Contudo, a heterogeneidade do meio rural deve ser levada em consideração no desenho dos contratos de fomento florestal. Variáveis como renda, qualidade de vida, educação, gênero, características familiares, aspectos regionais, culturais, dentre outros, tendem a ter impacto relevante na probabilidade de sucesso dos contratos de fomento florestal e na magnitude dos retornos por eles proporcionados (PEREIRA et al., 2004).

\section{Impactos do fomento florestal sobre o bem-estar das famílias. Capital humano e relações sociais e institucionais}

Embora não tenham sido coletadas medidas precisas de capital humano e da qualidade das relações sociais e institucionais em que se envolvem os fomentados, padrões observados sugerem que o fomento florestal pode contribuir positivamente em ambos os sentidos, mais precisamente enquanto fonte de conhecimento quanto às práticas agrícolas e silviculturais e, ainda, ampliando a sociabilidade entre os produtores rurais, e entre eles e os membros das empresas de base florestal. O que, neste último sentido, resulta da presença constante da empresa no meio dos produtores.

Os produtores fomentados afirmaram que aprenderam e aperfeiçoaram técnicas agrícolas a partir do contato com técnicos de fomento florestal. Resultado semelhante foi encontrado por Fischer (2009), em pesquisa no âmbito empresarial com sete representantes dos diferentes setores florestais, diferente do encontrado por Gomes (2005), identificando que as empresas não contribuíram para o estabelecimento de laços sociais mais sólidos às comunidades atuantes. No entanto, Oliveira (2002) e Santos e Martins (2007) observaram que as mudanças tecnológicas podem apresentar-se como um fator limitante para a adoção de uma tecnologia, sendo essa questão de transferência de tecnologia para o homem do campo um debate antigo que envolve aspectos culturais, sociais e tecnologia (CEZAR et al., 2000).

O fomento florestal no Jarí exerceu influência fracamente significativa nas relações de sociabilidade, onde fomentados frequentam mais espaços de sociabilidade do que não fomentados, sendo natural que um grupo de produtores com mesmos interesses procurem com maior frequência uns aos outros ou frequentem espaços comuns entre o grupo. Para Cuche (2002 apud SANTOS; MARTINS, 2007), o processo de concepção de um sistema cultural 
de agricultor depende do contexto onde está inserido e das relações com pessoas que compartilham um mesmo território, experiências e saberes.

Por outro lado, as relações institucionais de associativismo e cooperativismo não sofreram influência das atividades de fomento, mesmo diante da criação da Associação de Plantadores de Eucalipto do Pimental (ASPEP. O fator organização social entre classes é comprovado pela literatura, em que um grupo de mesmo interesse tende a formar associações, sindicatos e cooperativas, de forma que possam estar unidos e fortalecidos em função de um interesse comum (ABRAMOVAY; MAGALHÃES, 2007; COSTA, 2008; SILVA, 2002).

As relações institucionais também tendem a ser fortes e interferir diretamente nas unidades produtivas. No caso no Vale do Jarí, a empresa se mostrou fortemente atuante nas propriedades fomentadas (100\%), com a disponibilidade frequente de assistência técnica. Resultados semelhantes foram encontrados por (MORELLO, 2009). Já Rochadelle et al. (2008) encontraram situação oposta em pesquisa no Sul do Brasil, onde apenas 44\% dos fomentados relataram receber assistência técnica. As relações institucionais são ainda fortalecidas por meio da relação contratual, passando a atuar em parcerias para alcançar interesses mútuos (ABRAMOVAY; MAGALHÃES, 2007).

\section{Renda, capitalização e infraestrutura agrícola}

No geral, a proporção de famílias que em 2009 tiveram uma renda per capita menor que $1 / 2$ salário mínimo $(47 \%)$ está bem acima da proporção nacional $(22,90 \%)$. A alta renda de benefícios para os dois grupos estudados está ligada a um padrão nacional: quanto menor a renda per capita das famílias maior a parcela de contribuição de benefícios e pensões (IBGE, 2010).

A diferente composição da renda total dos grupos FO e NF representa as diferentes aptidões das duas classes para a agricultura. Por outro lado, a igualdade da renda per capita entre as duas categorias demonstra que apesar da baixa renda agropecuária da classe de não fomentos, estes estão nas mesmas condições financeiras que os não fomentados. A contribuição expressiva da renda extra, formada a partir de atividades pluriativas, constitui-se em uma estratégia de diversificação para assegurar a continuidade no meio rural (WANDERLEY, 2004).

Aspectos financeiramente importantes como renda per capita, capitalização e infraestrutura agrícola das famílias ainda não foram afetadas pela recente expansão de plantios florestais. 


\section{Balanço monetário do fomento florestal e remuneração da mão de obra familiar}

Os contratos do Grupo Orsa de fomento florestal regem 50\% dos valores do contrato de fomento, que podem ser liberados para a família em forma de insumos e recursos financeiros para manejo do plantio, podendo ser destinados ao pagamento de trabalhadores, ou ainda ficar como remuneração da mão de obra familiar.

Neste sentido, os resultados apontaram que o balanço de recursos financeiros de fomento não foi negativo (Figura 2). Todavia, o balanço positivo está relacionado com a disponibilidade de mão de obra familiar para a realização das atividades. Resultados semelhantes, com balanço monetário de investimentos negativos relacionados à baixa existência de mão de obra familiar, já foram identificados por Lopes et al. (2004) na produção de leite, onde a produção em pequena escala só é viável em caso de mão de obra exclusivamente familiar, diminuindo os custos de produção.

Por parte da empresa, a inviabilidade dos projetos pode estar relacionada com a distância dos centros de processamento (entre 70 e $150 \mathrm{~km}$ ) e com falta de acessibilidade e/ou estradas em péssimas condições. Morello (2009) identificou inviabilidade desses projetos para sete de nove microrregiões estudadas no estado de Minas Gerais. Malinovski et al. (2006) e Oliveira (1998) apontam inviabilidade em pequenas escalas, o que a contratação de mão de obra contribui para intensificar. Brandão et al. (2009) alertam quanto a inviabilidade de projetos de fomento florestal como alternativas para o desenvolvimento local, baseados em monoeconomia e falta de autonomia dos produtores. Por outro lado, Repassi et al. (2008) apontam para a viabilidade de cultivo de eucalipto solteiro, e ainda em forma de Sistemas Agroflorestais (SAFs), permitindo ao agricultor maior flexibilidade na comercialização de seus produtos e racionalização da mão de obra (SANTOS; PAIVA, 2002; RODIGHERI, 1998).

Quanto à baixa remuneração da mão de obra familiar empregada nas atividades, estudos realizados em Lavras (MG) por Lopes et al. (2004) comprovam que o pagamento de mão de obra familiar não é satisfatório para a produção leiteira. A marginalização da mão de obra rural também é relatada por Alves (2006), ao fazer uma relação da remuneração da mão de obra rural com a urbana, tendo como base de comparação a indústria de construção, os serviços de limpeza e o mercado informal. Na zona rural da região Norte, a renda bruta/ mês/pessoa ocupada é de R \$ 86,87 (Alves, 2006). 
Vale a pena lembrar que despesas com alimentação (para trabalhadores contratados) e equipamentos (correntes para motosserras, limas, combustíveis) não foram quantificados nessa análise, podendo ainda ser maior o déficit na balança de fomento florestal.

O fato é que para a empresa fomentadora a concepção de sucesso de um projeto como este, que leva em consideração apenas o número de produtores fomentados e expansão do projeto pela área de atuação da empresa, é diferente da concepção do produtor rural que, por sua vez, também é diferente da visão do governo e da ciência. Quando, na verdade, os fatores a serem considerados para avaliar o sucesso deste projeto são: 1) bem-estar e melhoria da qualidade de vida dos produtores; 2) impacto ambiental; 3) produção de eucalipto; 4) objetivos estratégicos da empresa.

\section{O futuro do fomento florestal}

Os contratos de fomento florestal são garantia de capitalização futura expressiva. Após o corte e venda da madeira dos projetos para a empresa fomentadora, a capitalização dos fomentados será, aproximadamente, nove vezes maior que a de não fomentados.

Outro aspecto importante a ser considerado é o declínio da produção de cultivos alimentícios com a adesão ao fomento florestal. Os resultados já apontam para implantação de áreas de cultivos insuficientes para manter a renda agrícola atual (de cultivos anuais) por parte dos fomentados (Tabela 2), podendo afetar futuramente a renda imediata e a segurança alimentar das famílias. Sachs (2007) aponta que a produção de biocombustíveis e carvão vegetal podem vir a competir por solos agriculturáveis com a produção alimentar, colocando esta última em cheque. Por outro lado, é importante considerar que a melhoria do poder aquisitivo ocasionado pela alta capitalização para os fomentados, após o corte da madeira, pode inibir o quadro de insegurança alimentar gerado pela baixa produção de alimentos, uma vez que, com a existência de recursos financeiros, as famílias podem comprar alimentos de qualidade.

A diminuição da implantação de áreas de cultivos anuais pelos fomentados está relacionada diretamente com o crescimento de áreas de plantios florestais e a inclinação do perfil das unidades produtivas à monocultura do eucalipto, decorrentes de uma realocação desproporcional da mão de obra e dos recursos disponíveis para a atividade silvicultural. Semelhante ao discutido por Ribeiro e Miranda (2009), o ideal é que a floresta plantada se adeque ao cronograma de execução de outras atividades realizadas nos estabelecimentos rurais. 


\section{CONCLUSÃO}

O fomento florestal, apesar de não ter rendido, nos primeiros quatro anos, acréscimo significativo na renda familiar da comunidade estudada, revelou ter contribuição positiva em dois aspectos socioeconômicos relevantes: (i) transferência de tecnologia silvicultural e agrícola; (ii) melhoria da qualidade das relações sociais intra-comunidade e comunidade-empresa, em que se destaca a criação de uma associação de produtores rurais.

A heterogeneidade dos grupos familiares revelou-se um fator preponderante para a adesão ao fomento florestal. Famílias maiores, com maior disponibilidade de mão de obra e produção agrícola com retorno garantido em médio e longo prazos (gado), ao fomento florestal. É preciso, portanto, levar em conta características como essas, e a heterogeneidade com as quais se manifestam, mesmo em pequenas comunidades, na elaboração dos contratos de fomento florestal, o que se mostra especialmente crítico, pelo fato de se tratar de uma atividade de maior porte do que as tradicionalmente desenvolvidas, em termos do investimento exigido e do volume de mão de obra necessária. A desconsideração destes aspectos pode acarretar em balanço monetário negativo no curto prazo, e decréscimo instantâneo na área dedicada à agricultura, o que aumenta a volatilidade da renda familiar.

\section{REFERÊNCIAS}

ABRAF-Associação Brasileira de Produtores de Florestas Plantadas. Anuário Estatístico: ano base 2006. Brasília, DF: ABRAF, 2007.

ABRAF-Associação Brasileira de Produtores de Florestas Plantadas. Anuário Estatístico: ano base 2009. Brasília, DF: ABRAF, 2010.

ABRAF-Associação Brasileira de Produtores de Florestas Plantadas. Anuário Estatístico: ano base 2010. Brasília, DF: ABRAF, 2011.

ABRAMOVAY, R.; MAGALHÃES, R. O acesso dos agricultores familiares aos mercados de biodiesel: parcerias entre grandes empresas e movimentos sociais. São Paulo: Regoverning Markets; RIMISP, 2007.

ALVES, E. (Ed.). Migração rural-urbana, agricultura familiar e novas tecnologias. Brasília: Embrapa, 2006. 184 p. 
BARLOW, J.; GARDNER T. A.; ARAUJO, I. S.; BONALDO, A. B.; COSTA, J. E.; ESPOSITO, M. C.; FERREIRA, L. V. ; HAWES, J.; HERNANDEZ, M. I. M.; LEITE, R. N.; LO-MAN-HUNG, N. F; MALCOLM, J. R.; MARTINS, M. B.; MESTRE, L. A. M.; NUNES-GUTJAHR, A. L.; OVERAL, W. L.; PARRY, L.; PETERS, S. L.; RIBEIRO-JUNIOR, M. A.; SILVA MOTTA, C. da; SILVA, M. N. F. da; PERES, C. A. Quantifying the biodiversity value of tropical primary, secondary and plantation forests. Proceedings of the National Academy of Science of the United States of America, v. 104, n. 47, p. 18555-18560, 2007. BRANDÃO, J. B; FROEHLICH, J. M.; BREITENBACH, R. Florestas de eucalipto como estratégia de desenvolvimento na fronteira-oeste: promessas e realidade. In: CONGRESSO SOBRE SOCIEDADE BRASILEIRA DE ECONOMIA, ADMINISTRAÇÃO E SOCIOLOGIA RURAL, 47, 2009. Anais... Porto Alegre: SOBER, 2009. Disponível em: < http://www.sober.org. br/palestra/13/286.pdf>. Acesso em: 15 jan. 2012.

BRASIL. Lei n ${ }^{\circ} 11.326$, de 24 de julho de 2006. Estabelece as diretrizes para a formulação da Política Nacional da Agricultura Familiar empreendimentos Familiares Rurais. Diário Oficial [da] República Federativa do Brasil, Brasília, DF, 25 jul. 2006. Seção 1, p. 1.

BROEK, A, R.; WIJKB, A.; TURKENBURGA, W. Farm-based versus industrial eucalyptus plantations for electricity generation in Nicaragua. Biomass and Bioenergy, v. 19, p. 295- 310, 2000.

CEZAR, I. M.; SKERRAT'T, S. DENT, J. B. Sistema participativo de geração e transferência de tecnologia para pecuaristas: o caso aplicado à Embrapa Gado de Corte. Cadernos de Ciência \& Tecnologia, v.17, n. 2, p.135-169, 2000.

CHAYANOV, A. V. La organización de la unidad económica campesina. Buenos Aires: Nueva Visión, 1974.

COSSALTER, C.; PYE-SMITH, C. Fast-wood forestry. Myths and realities. Center for International Forestry Research (CIFOR). Indonesia: Indonesia Printer, 2003. Disponível em: < www.cifor.cgiar.org/nc/online-library/browse/ view publication/publication/1257.html>. Acesso em: 28 jan. 2012.

COSTA, C. A. F. da. Associativismo, cooperativismo e economia solidária no Acre. T\&C Amazônia, v. 6, n.14. 2008. 
DESMOND, H.; RACE, D. Forestry out-grower schemes: a global view. Rome: Food and Agriculture Organization of the United Nations, 2001. (Forest Plantations Thematic Paper. Working Paper FP/11). Disponível em: <http:// www.fao.org/docrep/004/ ac131e/ ac131e00.htm >. Acesso em: 28 jan. 2012.

FERREIRA, M. Melhoramento e a silvicultura intensiva clonal. IPEF, n. 45, p.22-30, 1992.

FISCHER , A. O fomento na indústria de base florestal. Informe Gepec, v. 13, n. 2, p. 6-19, 2009.

FISCHER, A. Incentivos em programas de fomento florestal na indústria de celulose. 2007. Tese (Doutorado em Administração) - Faculdade de Economia, Administração e Contabilidade, Universidade de São Paulo, São Paulo, 2007.

GOMES, A. do N. Sustentabilidade de empresas de base florestal: o papel dos projetos sociais na inclusão das comunidades locais. Tese (Doutorado em Ciências Florestais) - Universidade Federal de Viçosa, Viçosa, 2005.

GRUPO ORSA. Relatório Anual de Sustentabilidade. 2010. Disponível em: < http://www.relatorioweb.com.br/orsa/10/node/70>. Acesso em: 28 jan. 2012. HERBOHN, J. L.; HARRISON, S. R. The Evolving Nature of Small-Scale Forestry in Australia. Journal of Forestry, v. 102, n. 1, p. 42-7, 2004.

HURTIENNE, T. Agricultura familiar e desenvolvimento rural sustentável na Amazônia. Novos Cadernos NAEA, v. 8, n. 1. p. 19-71, 2005.

IBGE-INSTITUTO BRASILEIRO DE GEOGRAFIA E ESTATÍSTICA. Síntese de indicadores sociais: uma análise das condições de vida da população brasileira. Rio de Janeiro: IBGE, 2010. (Estudos e Pesquisas informação Demográfica e Socioeconômica)

KAMARA, Y. Existing and potential forest financing mechanisms for smallholders and community forestry in West Africa. Initiatives Conseil International. Burkina Faso: Food and Agriculture Organization of the United Nations, 2011. Disponível em: <http://www.fao.org/forestry/2938808ff0e4c2d32fe144bcd715 dfb44a4fd7.pdf >. Acesso em: 28 jan.2012.

LOPES, M. A.; LIMA, A. L. R.; CARVALHO, F. de M.; REIS, R. P.; SANTOS, I. C.; SARAIVA, F. H. Controle gerencial e estudo da rentabilidade de sistemas de produção de leite na região de Lavras (MG). Ciênc. Agrotec., v. 28, n. 4, p. 883-89, 2004. 
MALINOVSKI, R. A.; BERGER, R.; SILVA, I. C.; MALINOVSKI, R. A; BARREIROS, R. M. Viabilidade econômica de reflorestamentos em área limítrofes de pequenas propriedades rurais no município de São José dos Pinhais-PR. Floresta, v. 36, n. 2, p. 261-274, 2006.

MORELLO, T. F. Carvão vegetal e siderurgia: de elo perdido a solução de um mundo pós-Kyoto. 2009. Dissertação (Mestrado em Economia) - Faculdade de Economia, Administração e Contabilidade, Universidade de São Paulo, São Paulo, 2009.

OliveirA, A. D.; LEITE, A. P.; BOTElHO, S. A.; SCOLFORO, J. R. S. Avaliação econômica da vegetação de cerrado submetida a diferentes regimes de manejo e de povoamentos de eucalipto plantado em monocultivo. Revista Cerne, v. 4, n. 1, p. 34-56, 1998.

OLIVEIRA, C.D. de S. Percepção de agricultura familiar na adaptação do sistema de cultivo de corte e trituração. 2002. 129f. Dissertação (Mestrado em Agriculturas Familiares e Desenvolvimento Sustentável) - Programa de PósGraduação em Agriculturas Amazônicas, Universidade Federal do Pará, Belém, 2002.

OLIVEIRA, F. R. Impacto Ambiental do Eucalipto na recarga de água subterrânea em área de cerrado, no médio vale do Jequitinhonha, Minas Gerais. In: CONGRESSO BRASILEIRO DE ÁGUAS SUBTERRÂNEAS, 12, 2002, Florianópolis. Anais... Florianópolis: ABAS, 2002. p. 1-10.

PEREIRA, S.; FIGUEIREDO, A.; LOUREIRO, R. Avaliação da política de agricultura familiar: uma abordagem de efeito-fixo. In: CONGRESSO DA SOBER: SOCIEDADE BRASILEIRA DE ECONOMIA, ADMINISTRAÇÃO E SOCIOLOGIA RURAL, 12, 2004. Cuiabá. Anais... Cuiabá, 2004.

REPASSI, R. M. A.; TARSITANO, M. A. A.; PEREIRA, J. C. dos R.; ARAUJO, C. A. M. Cultura do eucalipto na região de Suzanápolis, estado de São Paulo: análise econômica. Informações Econômicas, v.38, n. 4, p. 9-13, 2008.

REZENDE, J. L. P.; OLIVEIRA, A. D. de; COELHO-JUNIOR, L. M. Infinite planning horizon, land opportunity cost and faustmann methodology. Revista Cerne, v. 11, n. 2, p. 101-112, 2005.

RIBEIRO, A. B.; MIRANDA, G. de M. Estudo descritivo de programas de fomento em empresas florestais. Revista do Setor de Ciências Agrárias e Ambientais, v. 5, n. 1, p. 49-66, 2009. 
ROCHADELLI, R.; SILVA, J. C. G. L. da; RODRIGUES, F.; SCHNEIDER, A. V.; PETLA, D. Expansão florestal via fomento no segundo planalto paranaense: uma abordagem a partir da estrutura fundiária das propriedades rurais da região. Revista Cerne, v. 14, n. 2, p. 163-169, 2008.

RODIGHERI, H. R. Viabilidade econômica de plantios florestais solteiros e de sistemas agroflorestais. Brasília, DF: Embrapa Florestas, 1998. p.1-4. (Comunicado Técnico, n. 22).

SACHS, I. Integração dos agricultores familiares e dos empreendedores de pequeno porte na produção dos biocombustíveis. In: WORKSHOP DA FUNDAÇÃO BRASILEIRA DO DESENVOLVIMENTO SUSTENTÁVEL: "A Expansão da Agro-Energia e seus Impactos sobre os Ecossistemas Brasileiros", 1, 2007. Anais... Rio de Janeiro: FBDS, 2007. Disponível em: < http://www. conservation.org.br/publicacoes/files/4_Integracao_Agric_Fam_I_Sachs.pdf $>$. Acesso em: 15 nov. 2011.

SANTOS, L. de O. L. dos; MARTINS, S. R. Inovação tecnológica na agricultura familiar: um estudo de caso dos agricultores familiares do nordeste paraense. In: CONGRESSO BRASILEIRO DE SISTEMAS DE PRODUÇÃO, 7, 2007, Fortaleza. Anais ... Fortaleza: SBSP, 2007.

SANTOS, M. J. C. dos; PAIVA, S. N. de. Os sistemas agroflorestais como alternativa econômica em pequenas propriedades rurais: estudo de caso. Ciência Florestal, v. 12, n. 1, p. 135-141, 2002.

SEBILLOTTE, M. Agronomia y agricultura: ensaio de analises de las tareas del agrônomo. Boletim de Sistemas Agrários, n. 1, 1987.

SILVA, F. L.; GRIFFITH, J. J.; JACOVINE, L. A. G; VALADARES, J. H.; FERNANDES, M. A. S.; SILVA, E. C. G. Estudo da relação de confiança em programa de fomento florestal de indústria de celulose na visão dos produtores rurais. Revista Árvore, v. 33, n.4, p. 723-732, 2009.

SILVA, S. S. da. Associativismo/cooperatismo e os desafios para a automanutenção da produção camponesa na Amazônia-Acreana. Boletim de Geografia, v. 20, n. 2, p. 17-40, 2002.

VALVERDE, S. R. Plantações de eucalipto no Brasil. Revista da Madeira, v. 18, n. 107, p. 130, 2007. 
VIANA, M. B. O eucalipto e os efeitos ambientais do seu plantio em escala. Brasília, DF: Câmara dos Deputados; Consultoria Legislativa, 2004.

WANDERLEY, M. de N. B. Agricultura familiar e campesinato: rupturas e continuidade. Aula Inaugural - primeiro semestre de 2004. Rio de Janeiro: CPDA/UFRRJ, 2004.

ZIMMERMANN, C. L. Monocultura e transgenia: impactos ambientais e insegurança alimentar. Veredas do Direito, v. 6, n. 12, p.79-100, 2009. 